\title{
Pharmacokinetic and Pharmacodynamic Evaluation of Marbofloxacin in Pig against Korean Local Isolates of Actinobacillus pleuropneumoniae
}

\author{
Md. Akil Hossain, Hae-chul Park, Kyunghun Jeong, Yang ho Jang, Dae Gyun Kim, \\ JeongWoo Kang, and Kwang-jick Lee
} Veterinary Drugs \& Biologics Division, Animal and Plant Quarantine Agency (QIA), 177 Hyeoksin 8-ro,
Gimcheon-si, Gyeongsangbuk-do 39660, Republic of Korea

Correspondence should be addressed to JeongWoo Kang; hijach@korea.kr and Kwang-jick Lee; leekwj@korea.kr

Received 19 December 2016; Revised 24 February 2017; Accepted 6 March 2017; Published 6 April 2017

Academic Editor: Ronald E. Baynes

\begin{abstract}
Copyright (C) $2017 \mathrm{Md}$. Akil Hossain et al. This is an open access article distributed under the Creative Commons Attribution License, which permits unrestricted use, distribution, and reproduction in any medium, provided the original work is properly cited.

The pharmacokinetics of marbofloxacin in pigs after intravenous (i.v.), intramuscular (i.m.), and peroral (p.o.) administration and pharmacokinetic/pharmacodynamic indices of this drug against Korean local isolates of Actinobacillus pleuropneumoniae were determined in this study. Marbofloxacin $(2.50 \mathrm{mg} / \mathrm{kg}$ of body weight) was administered, and blood samples were collected with designated time intervals. Plasma-extracted marbofloxacin was injected into the LC-MS/MS system. The in vitro and ex vivo antibacterial activities of marbofloxacin were evaluated against 20 isolates of A. pleuropneumoniae. The mean peak plasma concentrations $\left(C_{\max }\right)$ after i.v., i.m., and p.o administration were $2.60 \pm 0.10,2.59 \pm 0.12$, and $2.34 \pm 0.12 \mu \mathrm{g} / \mathrm{mL}$ at $0.25 \pm 0.00$, $0.44 \pm 0.10$, and $1.58 \pm 0.40 \mathrm{~h}$, respectively. The area under the plasma concentration-time curves $\left(\mathrm{AUC}_{0-24}\right)$ and elimination halflives were $24.80 \pm 0.90,25.80 \pm 1.40$, and $23.40 \pm 5.00 \mathrm{~h} \cdot \mu \mathrm{g} / \mathrm{mL}$ and $8.60 \pm 0.30,12.80 \pm 1.10$, and $8.60 \pm 0.00$ h, for i.v., i.m., and p.o. administration, correspondingly. The $\mathrm{AUC}_{0-24}$ /MICs of marbofloxacin after i.v., i.m., and p.o. administration were $253.86 \pm 179.91$, $264.1 \pm 187.16$, and $239.53 \pm 169.75 \mathrm{~h}$, respectively. The $C_{\max } / \mathrm{MIC}$ values were $26.58 \pm 18.84,26.48 \pm 18.77$, and $23.94 \pm 16.97$, and $\mathrm{T}>\mathrm{MICs}$ were $42.80 \pm 1.01,36.40 \pm 1.24$, and $38.60 \pm 1.18$ h, after i.v., i.m., and p.o. administration, respectively. Thus, marbofloxacin dosage of $2.50 \mathrm{mg} / \mathrm{kg}$ of body weight by i.v., i.m., and p.o. administration with $24 \mathrm{~h}$ dosing interval will provide effective treatment for the infection of pig by A. pleuropneumonia.
\end{abstract}

\section{Introduction}

Marbofloxacin is one of the fluoroquinolones that were widely used in veterinary medicine and exhibits concentration-dependent bactericidal activity $[1,2]$. This antibiotic has a wide spectrum of activity, mainly against gram-negative pathogens, some gram-positive pathogens, and Mycoplasma $s p p$. [2]. Its properties of rapid absorption, good distribution, and broad spectrum against most of the swine respiratory pathogens, such as Haemophilus parasuis and Actinobacillus pleuropneumoniae, make it a good candidate to deal with a respiratory outbreak caused by any of these pathogens [3]. A. pleuropneumoniae is the causative agent of porcine pleuropneumonia, a worldwide disease with occasional clinical outbreaks that can have a severe economic impact [4].
Attempts to control the disease have been made by vaccination, treatment with antibiotics, and the establishment of herds free of the infection. Pigs can become asymptomatic carriers of the organism in their tonsils for long period of time $[5,6]$, thereby exposing susceptible animals and maintaining the disease in the herd. Moreover, pigs can carry $A$. pleuropneumoniae in their tonsils for several months without seroconverting [7]. Eradication of A. pleuropneumoniae from pig herds has been made with different antibiotics [4-7]. But, A. pleuropneumoniae is gaining resistance against all kinds of antibacterial agents including marbofloxacin [8].

It was reported that the resistance rates of fluoroquinolones were increasing in several European countries as well as in Korea, Taiwan, and Japan [8]. International organizations, such as the World Health Organization 
(WHO), the Food and Agriculture Organization of the United Nations (FAO), and the World Organization for Animal Health (OIE), as well as regulating authorities, have expressed their concern with the development of resistance in microorganisms that are pathogenic both for humans and animals particularly to some antimicrobial classes, including fluoroquinolones [9]. Currently, no fluoroquinolones are approved for use in poultry in the US [10]. The drugs are also prohibited in chicken farms in Australia, Finland, and Denmark [11]. Conversely, the law (number: 2014-1170) published in October 2014 in France targeted reducing the use of fluoroquinolones and third- and fourth-generation cephalosporins by $25 \%$ before December 2016, but not restricted completely [12]. Yet unpublished figures compiled by the British Poultry Council (BPC), which represent around $90 \%$ of the UK industries, reveal its members have increased their use of these drugs, using 1.126 tonnes of fluoroquinolones in 2014 compared with 0.71 tonnes in the previous year, which indicates that these antimicrobials are still in use in many countries [11].

However, there are recent concerns about the emergence of quinolone-resistant bacterial strains and the impact of improper use of these drugs on human and animal; fluoroquinolones are still an important antimicrobial medicine. Thus, there is an important need to use fluoroquinolones with caution to preserve their effectiveness for many years. In veterinary medicine, it is essential to reserve these drugs for cases requiring a powerful antibiotic and to prescribe and/or administer them only under a good clinical assessment and with appropriate regimens [12]. Because, the selection of improper dose and dose intervals are accelerating the resistance against these drugs [13-16]. The study of pharmacokinetics and pharmacodynamics and their integration is the major tool to determine the dosage regimens appropriately. The determination of pharmacokinetic parameters and their interspecies differences helps to minimize dosage errors. The pharmacokinetics of marbofloxacin have been investigated in different animals and it demonstrated an almost $100 \%$ bioavailability, higher concentration in plasma and peripheral tissues in goats [17], cows [18], cats [19], sheep [20], dogs [21], and pigs [22, 23]. Although, some studies have been published on the pharmacokinetics of marbofloxacin in animals including pigs $[3,18-22,24,25]$, yet the pharmacokinetic data of marbofloxacin in pig tissues and plasma is not sufficient enough to predict the efficacy of this drug precisely. Furthermore, the integration of pharmacokinetic (PK) data with pharmacodynamic (PD) data helps to establish the PK/PD indices (AUC/MIC, $C_{\max } / \mathrm{MIC}, T>\mathrm{MIC}, \mathrm{AUC}>$ MIC, etc.) which are fundamental to predict efficacy and minimize resistance development $[26,27]$.

Since there are contradicting values in PK/PD indices which correlate with prevention of resistant mutant selection and efficacy $[28,29]$, determining PK/PD indices specific to a particular pathogen and antimicrobial agent has received great attention. The integration of PK data with the time course activity (ex vivo) of marbofloxacin against A. pleuropneumoniae has not been studied in pigs. Thus, it was intended firstly to develop and validate a sensitive and reliable LC-MS/MS method for attaining the ultimate goal while the prime objective of this study was to characterize the pharmacokinetics of marbofloxacin following i.v., i.m., and p.o. administration at a dose of $2.50 \mathrm{mg} / \mathrm{kg}$ of body weight in pigs and to explore in vivo and ex vivo $\mathrm{PK} / \mathrm{PD}$ indices using Korean local pathogenic strains of A. pleuropneumoniae as a model bacterium.

\section{Materials and Methods}

2.1. Chemical Reagents and Media. Marbofloxacin (Marbocyl $10 \%$ solution) was purchased from Vetoquinol Ltd. (Lure, France). Marbofloxacin reference standard was purchased from United States Pharmacopeial Convention (Rockville, $\mathrm{MD}$, USA). Mueller-Hinton broth (MHB) and chocolate agar media were obtained from Difco Laboratories (Detroit, MI, USA), and veterinary fastidious medium (VFM) was from Thermo Fisher Scientific (Waltham, MA, USA). Other reagents and chemicals were of analytical grade. Purified water was prepared using the Milli-Q water purification system from Millipore, Inc. (Bedford, MA, USA).

2.2. Animal Experimental Procedure. The study was carried out in 12-week-old castrated cross-bred (Duroc $\times$ Landrace $\times$ Yorkshire) healthy male pigs at Animal and Plant Quarantine Agency, Gimcheon-si, South Korea. Pigs with body weight of about $30 \mathrm{~kg}$ were purchased from the Sunjin CU farm (Icheon, Gyeonggi-do, South Korea). All animals were kept in a self-contained animal unit. Commercial antibiotic-free feed and fresh water were provided ad libitum throughout the experimental period. The pigs were fasted for overnight $(\sim 12 \mathrm{~h})$ and randomly divided into 3 groups, where 4 pigs were assigned in each group. Marbofloxacin (Marbocyl 10\% Solution, Vetoquinol Ltd., Lure, France) at a dose of $2.5 \mathrm{mg} / \mathrm{kg}$ of body weight was administered to different groups of animals through i.v., i.m., and p.o. routes for the determination of the basic pharmacokinetic parameters. All animal experimental procedures were approved by the Institutional Animal Care and Use Committee of Animal and Plant Quarantine Agency, Gimcheon-si, South Korea (approval number: 2014-2190).

2.3. Blood Collection and Sample Preparation. The blood samples $(5 \mathrm{~mL})$ were taken in heparinized Vacutainer tubes by puncturing of jugular vein at $0 \mathrm{~min}, 15 \mathrm{~min}, 30 \mathrm{~min}$, $45 \mathrm{~min}, 1 \mathrm{~h}, 1.5 \mathrm{~h}, 2 \mathrm{~h}, 3 \mathrm{~h}, 6 \mathrm{~h}, 9 \mathrm{~h}, 12 \mathrm{~h}, 18 \mathrm{~h}, 24 \mathrm{~h}, 30 \mathrm{~h}, 36 \mathrm{~h}$, $48 \mathrm{~h}, 60 \mathrm{~h}, 72 \mathrm{~h}$, and $120 \mathrm{~h}$ from all of these animals. The blood samples were centrifuged at $2000 \times \mathrm{g}$ for $10 \mathrm{~min}$ at $4^{\circ} \mathrm{C}$ to obtain the plasma. The plasma samples $(500 \mu \mathrm{L})$ were mixed with $1.5 \mathrm{~mL}$ of $0.1 \%$ formic acid in acetonitrile to precipitate plasma proteins. After shaking for $20 \mathrm{~min}$, the mixtures were centrifuged at $5000 \times \mathrm{g}$ for $30 \mathrm{~min}$. The solvents of the supernatants were evaporated under nitrogen flow at $50^{\circ} \mathrm{C}$ to make the volume about $500 \mu \mathrm{L}$ and then stored in $-70^{\circ} \mathrm{C}$ refrigerator.

2.4. LC-MS/MS Analysis. Liquid chromatography-tandem mass spectrometry (LC-MS/MS) with gradient elution through YMC C $\mathrm{C}_{18}(3.0 \times 100 \mathrm{~mm}, 3 \mu \mathrm{m})$ column was utilized to determine the content of marbofloxacin in plasma by 
TABLE 1: Mass to charge ratios $(\mathrm{m} / z)$, collision energies $(\mathrm{CE})$ of precursor ions, quantification ions, and confirmation ions.

\begin{tabular}{|c|c|c|c|}
\hline Substance & $\begin{array}{c}\text { Precursor ion } \\
m / z\end{array}$ & $\begin{array}{c}\text { Quantification ions } \\
m / z(\mathrm{CE}, \mathrm{eV})\end{array}$ & $\begin{array}{c}\text { Confirmation ions } \\
m / z(\mathrm{CE}, \mathrm{eV})\end{array}$ \\
\hline Marbofloxacin & 363 & $72(110,20)$ & $320(110,15)$ \\
\hline
\end{tabular}

analyzing $5 \mu \mathrm{L}$ aliquot of each samples. The mobile phase was a mixture of (A) $0.1 \%$ formic acid in distilled water and (B) $0.1 \%$ formic acid in acetonitrile, where the ratios of " $\mathrm{A}$ " and " $\mathrm{B}$ " were different and maintained in a gradient flow. The initial composition of mobile phase was $90 \%$ of " $\mathrm{A}$ " and $10 \%$ of "B" which was linearly changed to $100 \%$ of "B" from 0.1 to $3 \mathrm{~min}$ and maintained this ratio up to $4.9 \mathrm{~min}$. At $5 \mathrm{~min}$, the ratio was directly returned to its base composition $(10 \% \mathrm{~B})$ and maintained this composition up to the end of the acquisition. The flow rate was $0.6 \mathrm{~mL} / \mathrm{min}$, and the injection volume was $5 \mu \mathrm{L}$. Tandem mass spectrometry with electrospray ionization was used and maintained in positive mode. The mass to charge ratios $(\mathrm{m} / z)$ of precursor ions, quantification ions and confirmation ions, and the collision energies (CE) of marbofloxacin are listed in Table 1. The method was optimized and validated prior to applying for PK analysis.

2.5. Validation of the Analytical Method. Specificity was determined from three blanks and pooled plasma samples which were analyzed to note the absence of interferences in the elution position of marbofloxacin. Stock solution of marbofloxacin $(1 \mathrm{mg} / \mathrm{mL})$ was prepared by dissolving a pure reference standard of marbofloxacin in aqueous solution of $0.1 \%$ formic acid to stabilize the $\mathrm{pH}$ for establishing the linearity. Further dilutions of the stock solution were prepared, and the drug solutions of different concentrations were spiked into blank plasma to produce calibration curves. Linearity was determined by a series of three injections of six plasma samples spiked with $(5,10,50,100,500$, and $1000 \mathrm{ng} / \mathrm{mL}$ ) marbofloxacin. Pooled plasma samples were spiked with known concentrations (10 and $100 \mathrm{ng} / \mathrm{mL}$ ) of marbofloxacin and deproteinated with acetonitrile for the determination of accuracy and recovery. After extraction of the analyte from the matrix and injection to the analytical instrument, the recovery was determined by comparing the resulting peak response with those of other samples to which the same corresponding concentrations of the drug had been added just before the injection.

Repeatability and reproducibility were studied on six injections from spiked plasma samples of three different concentrations. The detection limit and quantitation limit were determined from the calibration curve by analyzing marbofloxacin spiked samples. The limit of detection (LOD) was calculated from the standard deviation of responses and the slope obtained from the calibration curve as stated by the following equation: $\operatorname{LOD}=(3.3 \times \mathrm{SD}) /$ slope $[30,31]$. The limit of quantitation (LOQ) was calculated from the standard deviation (SD) of responses and the slope associated with the calibration curve, according to the following equation: LOQ $=(10 \times \mathrm{SD}) /$ slope $[30,31]$.
2.6. Pharmacokinetic Study. The concentrations of marbofloxacin in plasma samples of different time points were analyzed by LC-MS/MS. The pharmacokinetic parameters of marbofloxacin were analyzed by WinNonlin 6.1 software (Pharsight Corporation, Mountain View, CA, USA). The area under the curve (AUC), peak times $\left(T_{\max }\right)$, peak plasma concentrations $\left(C_{\max }\right)$, elimination half-life $\left(T_{1 / 2}\right)$, and absolute bioavailability $(F)$ were calculated for pharmacokinetic determination using a noncompartmental analysis. The absolute bioavailability for i.m. administration was determined with the formula $F=\left(\mathrm{AUC}_{\mathrm{im}} / \mathrm{AUC}_{\mathrm{iv}}\right) \times 100 \%$. Similarly, absolute bioavailability was determined by $F=\left(\mathrm{AUC}_{\mathrm{po}} / \mathrm{AUC}_{\mathrm{iv}}\right) \times$ $100 \%$, in the case of p.o. administration. $\mathrm{AUC}_{\mathrm{iv}}, \mathrm{AUC}_{\mathrm{im}}$, and $\mathrm{AUC}_{\mathrm{po}}$ are obtained after i.v., i.m., and p.o. administration, respectively. Pharmacokinetic parameters were calculated for each individual animal and are presented as arithmetic means $\pm \mathrm{SD}$.

2.7. Ex Vivo Experiment. Plasma samples were collected from pigs after $0,1 / 4,3 / 4,2,9$, and $24 \mathrm{~h}$ of marbofloxacin administration via i.v., i.m., and p.o., which were used for ex vivo experiment. Controls were prepared from plasma samples collected from those pigs which did not receive any drug. About $170 \mu \mathrm{L}$ of VFM (veterinary fastidious medium) was added to each well of a 96-well microtitre plate. The bacterial cultures $(20 \mu \mathrm{L})$ of $A$. pleuropneumoniae $(n=20)$ from the stationary-phase of growth were individually added to $10 \mu \mathrm{L}$ of plasma and mixed with the $170 \mu \mathrm{L}$ of VFM in each well to give a final concentration of approximately $10^{6} \mathrm{CFU} / \mathrm{mL}$. One hundred microlitre of sample was collected at each time point, serially diluted, and spread over chocolate agar media. The bacteria in plates were further incubated at $35^{\circ} \mathrm{C}$ with $5 \% \mathrm{CO}_{2}$ for $24 \mathrm{~h}$. After incubation, bacteria colonies were manually counted.

2.8. Pharmacodynamic Study. The minimum inhibitory concentration (MIC) and minimum bactericidal concentration (MBC) of marbofloxacin against 20 isolates of A. pleuropneumoniae were determined by using Mueller-Hinton broth (MHB) and Mueller-Hinton Agar (MHA) according to the standard broth microdilution method as described in Clinical and Laboratory Standards Institute (CLSI) guideline [32]. Marbofloxacin was serially diluted twofold horizontally from first well to tenth well in 96-well plates where the final concentrations would be from 32 to $0.00391 \mu \mathrm{g} / \mathrm{mL}$ after inoculation of bacterial culture. Bacterial culture from midlogarithmic phase was diluted and $100 \mu \mathrm{L}$ of the diluted bacterial suspension was added to serially diluted-drug solutions in 96-well plates where the final inoculum density would be approximately $5 \times 10^{5} \mathrm{CFU} / \mathrm{mL}$. The bacteria in presence of drug substances in 96 -well plates were incubated at $35^{\circ} \mathrm{C}$ for 
TABLE 2: Validation parameters of marbofloxacin by LC-MS/MS.

\begin{tabular}{|c|c|c|c|c|c|c|c|c|}
\hline \multirow{2}{*}{ Analyte } & \multirow{2}{*}{$\mathrm{RT}(\min )$} & \multirow{2}{*}{ Correlation coefficient $\left(r^{2}\right)$} & \multicolumn{4}{|c|}{ Average recovery (\%) Coefficient of variation (\%) } & \multirow{2}{*}{$\mathrm{LOD}(\mathrm{ng} / \mathrm{mL})$} & \multirow{2}{*}{ LOQ $(\mathrm{ng} / \mathrm{mL})$} \\
\hline & & & $10 \mathrm{ng} / \mathrm{mL}$ & $100 \mathrm{ng} / \mathrm{mL}$ & $10 \mathrm{ng} / \mathrm{mL}$ & $100 \mathrm{ng} / \mathrm{mL}$ & & \\
\hline Marbofloxacin & 2.4 & 0.9999 & 92 & 87 & 4 & 5 & 2 & 5 \\
\hline
\end{tabular}

TABLE 3: Pharmacokinetic parameters of marbofloxacin following intravenous, intramuscular, and peroral administration using WinNonlin $(n=4$, mean $\pm \mathrm{SD})$.

\begin{tabular}{lcccc}
\hline Parameters & Unit & i.v. & i.m. & p.o. \\
\hline$T_{1 / 2}$ & $\mathrm{~h}$ & $8.60 \pm 0.30$ & ${ }^{*} 12.8 \pm 1.10$ & $8.60 \pm 0.00$ \\
$T_{\max }$ & $\mathrm{h}$ & $0.25 \pm 0.00$ & $0.44 \pm 0.10$ & ${ }^{*} 1.58 \pm 0.40$ \\
$C_{\max }$ & $\mu \mathrm{g} / \mathrm{mL}$ & $2.60 \pm 0.10$ & $2.59 \pm 0.12$ & $2.34 \pm 0.12$ \\
$\mathrm{AUC}_{0-24}$ & $\mathrm{~h} \cdot \mu \mathrm{g} / \mathrm{mL}$ & $24.80 \pm 0.90$ & $25.8 \pm 1.40$ & $23.40 \pm 5.00$ \\
$F$ & $\%$ & - & $104.60 \pm 5.70$ & $94.35 \pm 8.90$ \\
\hline
\end{tabular}

i.v.: intravenous, i.m.: intramuscular, p.o.: peroral, and $T_{1 / 2}$ : elimination half-life. $T_{\max }$ : time of maximum concentration; $C_{\max }$ : maximum concentration after administration; $\mathrm{AUC}_{0-24}$ : area under the serum concentration-time curve from time zero to $24 \mathrm{~h}$; and $F$ : bioavailability. ${ }^{*}$ Significantly different among groups.

$18 \mathrm{~h}$. After incubation, the lowest concentration that inhibited visible growth of microorganism was considered as MIC. Cultures $(20 \mu \mathrm{L})$ from all microwells in 96-well plates that showed no visible growth were spotted on Tryptic Soy Agar (TSA) plates and incubated for $24 \mathrm{~h}$ at $35^{\circ} \mathrm{C}$. The lowest concentration that completely inhibited growth on agar plate was considered as minimum bactericidal concentration $(\mathrm{MBC})$. All experimentations were performed in triplicate.

2.9. Data Analysis. Data are presented as mean \pm standard deviation of three replicate assays. Analysis of variance (ANOVA) and $F$-test were performed and $P$ values of less than 0.05 were considered to be statistically significant.

\section{Results}

3.1. Validation of Analytical Method. The method validation was performed in the sample matrix. Good linearity $\left(R^{2}>\right.$ 0.999) was observed, and the quantified average recoveries of marbofloxacin were $87-92 \%$ at the level of 10 to $100 \mathrm{ng} / \mathrm{mL}$. The within-run precision (percent coefficient of variation, $\% \mathrm{CV}$ ) for the described method was less than $10 \%$ over the range of concentrations studied. The limits of detection (LOD) and the limit of quantification (LOQ) were 2 and $5 \mathrm{ng} / \mathrm{mL}$, respectively. The validation data of the analytical method is presented in Table 2, and the representative LCMS/MS chromatograms of blank serum and standard and spiked sample solutions are shown in Figure 1.

3.2. Pharmacokinetics of Marbofloxacin in Plasma. The concentrations of marbofloxacin in plasma at different time intervals after i.v., i.m., and p.o. administration are presented in Figure 2. Pharmacokinetic parameters of marbofloxacin after i.v., i.m., and p.o. administrations are shown in Table 3. The peak plasma concentrations $\left(C_{\max }\right)$ of marbofloxacin were $2.60 \pm 0.10 \mu \mathrm{g} / \mathrm{mL}, 2.59 \pm 0.12 \mu \mathrm{g} / \mathrm{mL}$, and $2.34 \pm 0.12 \mu \mathrm{g} / \mathrm{mL}$ for i.v., i.m., and p.o. administration, respectively. The areas under the plasma concentration-time curves $\left(\mathrm{AUC}_{0-24}\right)$ were $24.80 \pm 0.90,25.80 \pm 1.40$, and $23.40 \pm 5.00 \mathrm{~h} \cdot \mu \mathrm{g} / \mathrm{mL}$ for i.v., i.m., and p.o. administration, correspondingly. The elimination half-life $\left(T_{1 / 2}\right)$ values were $8.60 \pm 0.30,12.80 \pm 1.10$, and $8.60 \pm 0.00 \mathrm{~h}$, correspondingly in i.v., i.m., and p.o. administration. Absolute percentages of bioavailability $(F)$ of the marbofloxacin in pig were $104.60 \pm 5.70 \%$ and 94.35 $\pm 8.90 \%$, respectively, in intramuscular and peroral routes compared to intravenous route.

3.3. Ex Vivo Antibacterial Effect. The time-dependent antibacterial effects of marbofloxacin against A. pleuropneumoniae in ex vivo condition were determined in plasma samples which were collected at $0,1 / 4,3 / 4,2,9$, and $24 \mathrm{~h}$ after i.v., i.m., and p.o. administration of marbofloxacin in pigs (Figure 3). The addition of plasma samples which were collected at $1 / 4 \mathrm{~h}$ to $9 \mathrm{~h}$ after the i.v. administration of marbofloxacin showed bactericidal effect within $12 \mathrm{~h}$ of incubation. The supplementation of plasma that was collected at $24 \mathrm{~h}$ of marbofloxacin administration showed a significant reduction of bacterial growth $(\log \mathrm{CFU} / \mathrm{mL})$ at different time points before $24 \mathrm{~h}$ and completely eliminated the bacteria at $24 \mathrm{~h}$ of incubation. The incubation of bacteria in presence of plasma samples which were collected after i.m. administration also demonstrated similar trend of bacterial elimination. When A. pleuropneumoniae isolates were incubated with the addition of plasma which were collected at $3 / 4,2$, and $9 \mathrm{~h}$ of administration through p.o. route, they also displayed bactericidal effect. However, there were no noticeable variations in bacterial $(\log \mathrm{CFU} / \mathrm{mL})$ growth, when the plasma samples were collected at $1 / 4$ and $24 \mathrm{~h}$ of p.o. administration and the bacteria were incubated in presence of those plasma samples.

3.4. In Vitro MICs and MBCs of Marbofloxacin. The MICs and MBCs of marbofloxacin against 20 isolates of $A$. pleuropneumonia were determined. The MICs of marbofloxacin against these isolates were ranged from 0.03152 to $1.00 \mu \mathrm{g} / \mathrm{mL}$. The MBCs of this antimicrobial drug against those strains of A. pleuropneumoniae were from 0.0625 to $8.00 \mu \mathrm{g} / \mathrm{mL}$. The ratio of MIC and MBC was 1 for 6 strains out of 20. The MBC values were 2 - to 16 -fold higher than MIC values against most 


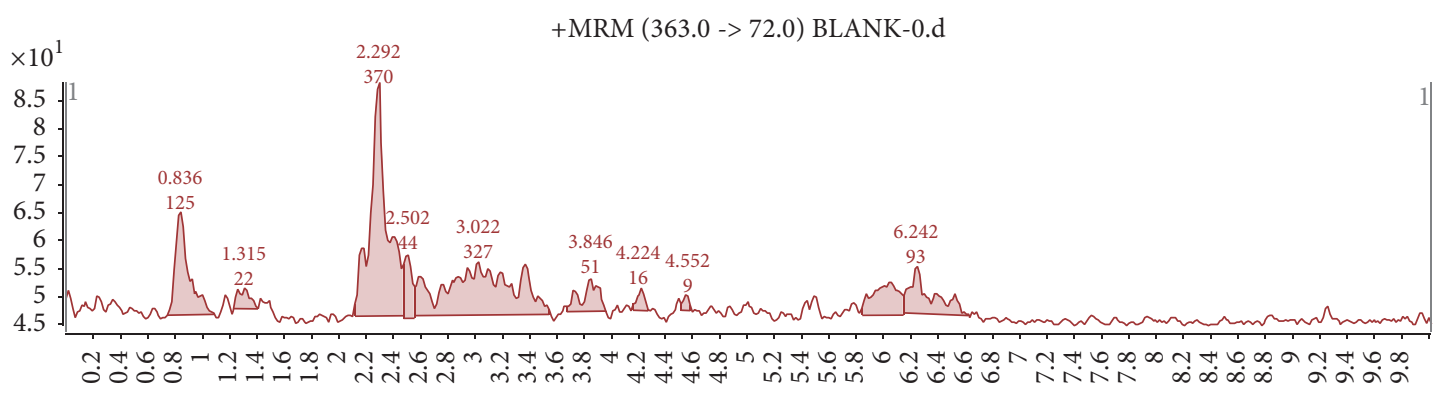

Counts versus acquisition time (min)

(a)

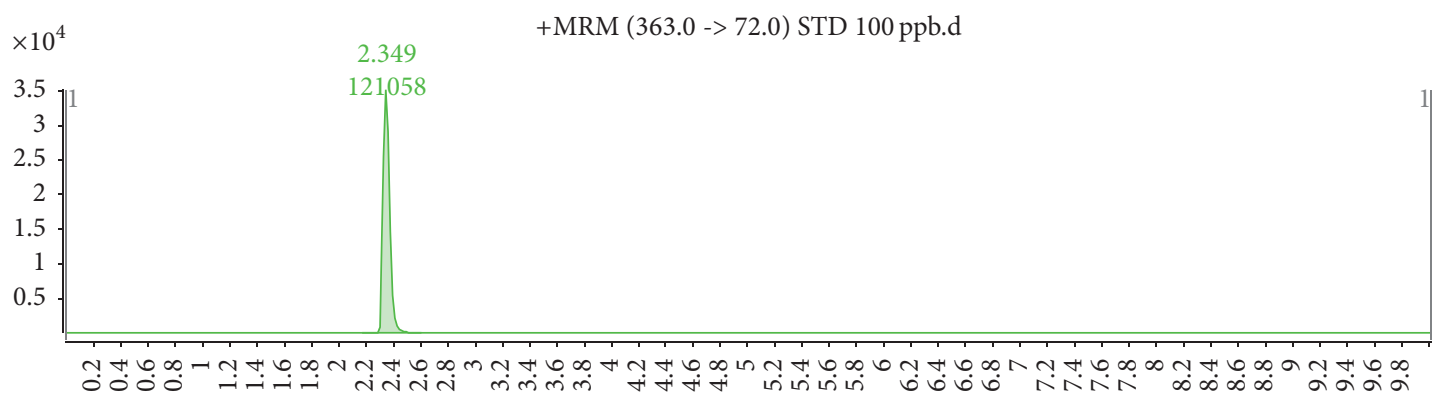

Counts versus acquisition time (min)

(b)

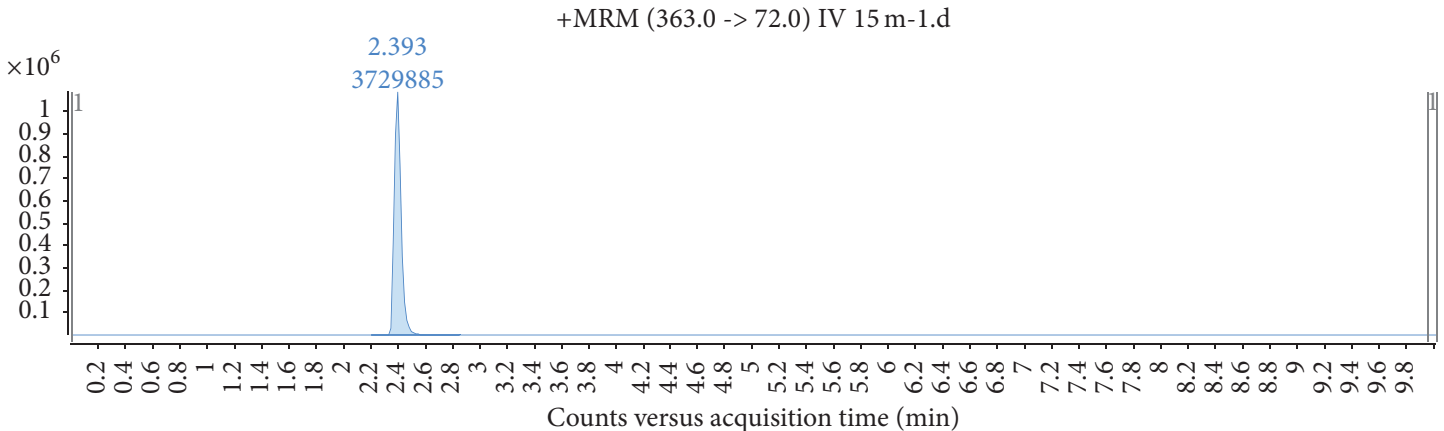

(c)

Figure 1: Mass chromatograms of (a) blank plasma, (b) standard marbofloxacin solution, and (c) marbofloxacin spiked plasma samples. (This figure is obtained from the LC-MS/MS system and it is not possible to edit).

of the strains. The MIC, MBC, and the ratio of MIC and $\mathrm{MBC}$ for each strain are presented in Table 4.

3.5. $P K / P D$ Integration of Marbofloxacin in Serum. The in vitro $\mathrm{MIC}$ and $\mathrm{MBC}$ data were integrated with in vivo $\mathrm{PK}$ data to determine the $\mathrm{PK} / \mathrm{PD}$ indices such as $\mathrm{AUC}_{0-24} / \mathrm{MIC}$, $\mathrm{AUC}_{0-24} / \mathrm{MBC}, C_{\max } / \mathrm{MIC}, C_{\max } / \mathrm{MBC}, T>\mathrm{MIC}$, and $\mathrm{AUC}_{0-24}>\mathrm{MIC}$, which are presented in Table 5 . The $\mathrm{AUC}_{0-24} / \mathrm{MIC}$ and $\mathrm{AUC}_{0-24} / \mathrm{MBC}$ ratios of marbofloxacin against $A$. pleuropneumoniae after i.v., i.m., and p.o. administration were $253.86 \pm 179.91,264.1 \pm 187.16$, and $239.53 \pm$ $169.75 \mathrm{~h}$ and $144.93 \pm 143.35,150.77 \pm 149.13$, and $136.74 \pm$ $135.26 \mathrm{~h}$, respectively. The time where the plasma concentration exceeds MIC ( $T>$ MIC) after i.v., i.m., and p.o. administration was $42.80 \pm 1.010,36.40 \pm 1.24$, and 38.60 $\pm 1.18 \mathrm{~h}$, respectively. The $\mathrm{AUC}_{0-24} / \mathrm{MIC}, \mathrm{AUC}_{0-24} / \mathrm{MBC}$,
$C_{\max } / \mathrm{MIC}$, and $C_{\max } / \mathrm{MBC}$ values attained from the application of marbofloxacin through p.o. route are significantly lower than i.v. and i.m. administration values. On the contrary, the $\mathrm{AUC}_{0-24}>\mathrm{MIC}$ value with the administration of marbofloxacin through p.o. route is significantly higher than the values obtained from i.v. and i.m. administration. There were no noticeable variations in $\mathrm{PK} / \mathrm{PD}$ indices of plasma samples collected after i.v. and i.m. administration to pigs.

\section{Discussion}

In the current study, a sensitive and reliable LC-MS/MS method is developed for the rapid detection of marbofloxacin in plasma. This validated method was applied in determining pharmacokinetics and pharmacokinetic-pharmacodynamic indices of marbofloxacin after i.v., i.m., and p.o. administration in pigs. The pharmacokinetic study of marbofloxacin 
Concentration of marbofloxacin in serum

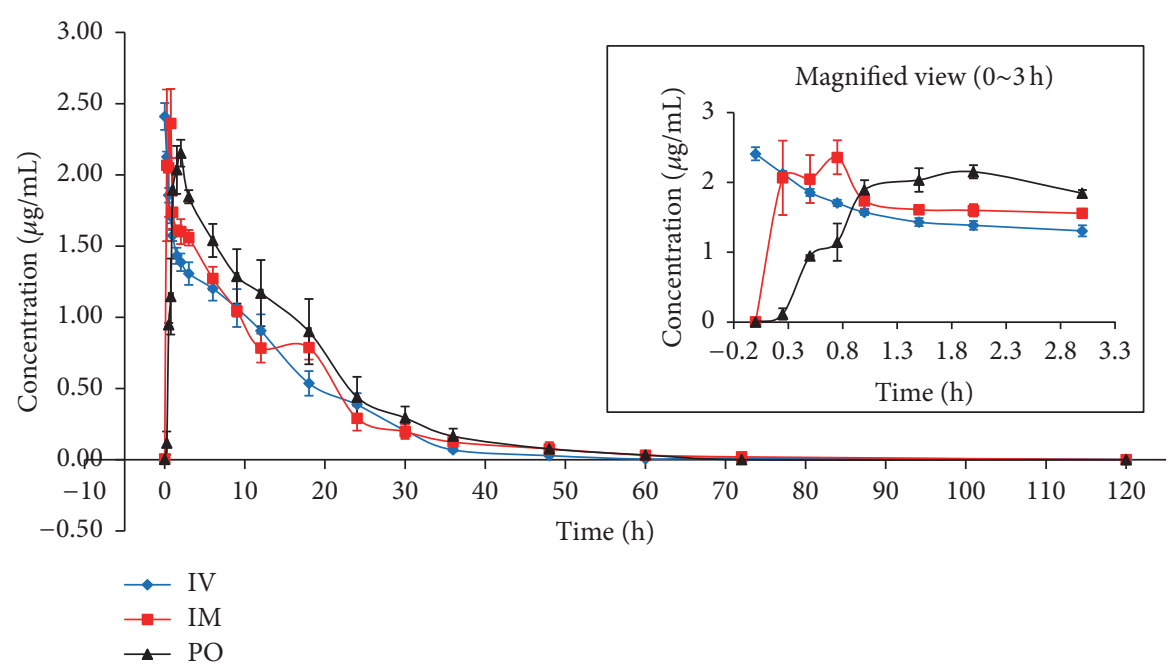

FIGURE 2: The plasma concentrations (mean $\pm \mathrm{SD}$ ) of marbofloxacin versus time after intravenous, intramuscular, and peroral administration to pigs.

TABLE 4: The pharmacodynamic parameters of marbofloxacin against 20 isolates of Actinobacillus pleuropneumonia.

\begin{tabular}{|c|c|c|c|c|}
\hline Strain number & Concentration range $(\mu \mathrm{g} / \mathrm{mL})$ & $\operatorname{MIC}(\mu \mathrm{g} / \mathrm{mL})$ & $\mathrm{MBC}(\mu \mathrm{g} / \mathrm{mL})$ & $\mathrm{MBC} / \mathrm{MIC}$ \\
\hline 1 & $32-0.00391$ & 0.0625 & 0.0625 & 1 \\
\hline 2 & $32-0.00391$ & 0.0625 & 0.25 & 4 \\
\hline 3 & $32-0.00391$ & 0.125 & 0.125 & 1 \\
\hline 4 & $32-0.00391$ & 0.125 & 0.125 & 1 \\
\hline 5 & $32-0.00391$ & 0.0625 & 0.5 & 8 \\
\hline 6 & $32-0.00391$ & 0.125 & 0.25 & 2 \\
\hline 7 & $32-0.00391$ & 0.125 & 1 & 8 \\
\hline 8 & $32-0.00391$ & 0.125 & 0.25 & 2 \\
\hline 9 & $32-0.00391$ & 0.125 & 0.25 & 2 \\
\hline 10 & $32-0.00391$ & 0.0625 & 0.0625 & 1 \\
\hline 11 & $32-0.00391$ & 0.5 & 2 & 4 \\
\hline 12 & $32-0.00391$ & 0.5 & 2 & 4 \\
\hline 13 & $32-0.00391$ & 0.0625 & 0.25 & 4 \\
\hline 14 & $32-0.00391$ & 0.125 & 0.125 & 1 \\
\hline 15 & $32-0.00391$ & 0.25 & 2 & 8 \\
\hline 16 & $32-0.00391$ & 0.125 & 0.25 & 2 \\
\hline 17 & $32-0.00391$ & 0.0313 & 0.0625 & 2 \\
\hline 18 & $32-0.00391$ & 0.0625 & 0.0625 & 1 \\
\hline 19 & $32-0.00391$ & 1 & 8 & 8 \\
\hline 20 & $32-0.00391$ & 0.25 & 4 & 16 \\
\hline
\end{tabular}

TABLE 5: Pharmacokinetic/pharmacodynamic integration of marbofloxacin in pig after administration through intravenous, intramuscular, and peroral routes.

\begin{tabular}{lcccc}
\hline Parameters & Units & i.v. & i.m. & p.o. \\
\hline $\mathrm{AUC}_{0-24} / \mathrm{MIC}$ & $\mathrm{h}$ & $253.86 \pm 179.91$ & $264.1 \pm 187.16$ & $239.53 \pm 169.75^{*}$ \\
$C_{\max } / \mathrm{MIC}$ & - & $26.58 \pm 18.84$ & $26.48 \pm 18.77$ & $23.94 \pm 16.97^{*}$ \\
$\mathrm{AUC}_{0-24} / \mathrm{MBC}$ & $\mathrm{h}$ & $144.93 \pm 143.35$ & $150.77 \pm 149.13$ & $136.74 \pm 135.26^{*}$ \\
$C_{\max } / \mathrm{MBC}$ & - & $15.18 \pm 15.01$ & $15.12 \pm 14.95$ & $13.67 \pm 13.52^{*}$ \\
$T>$ MIC & - & $42.80 \pm 1.010$ & $36.40 \pm 1.24$ & $38.60 \pm 1.18$ \\
$\mathrm{AUC}>$ MIC & - & $20.90 \pm 0.90$ & $20.40 \pm 1.40$ & $26.50 \pm 5.00^{*}$ \\
\hline
\end{tabular}

i.v.: intravenous, i.m.: intramuscular, and p.o.: peroral. * Significantly different among groups. 


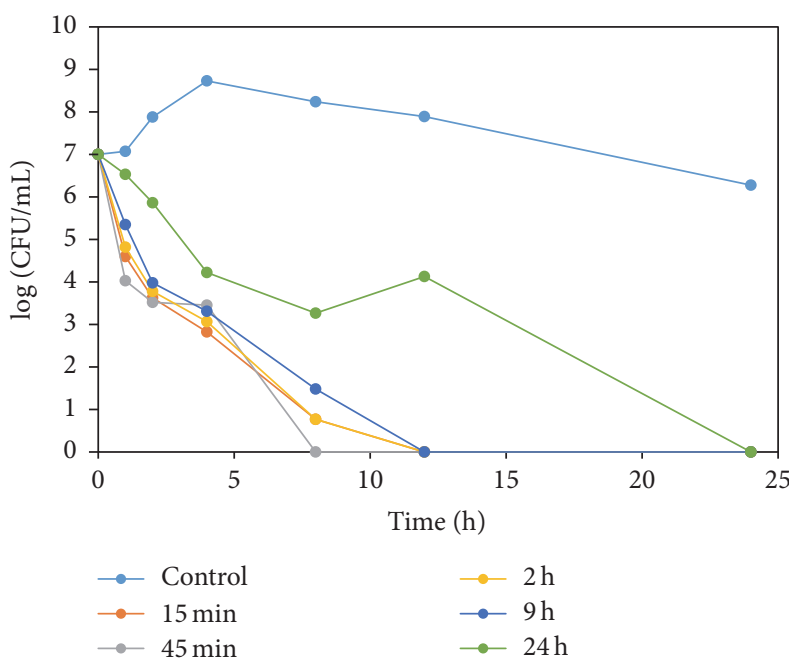

(a)

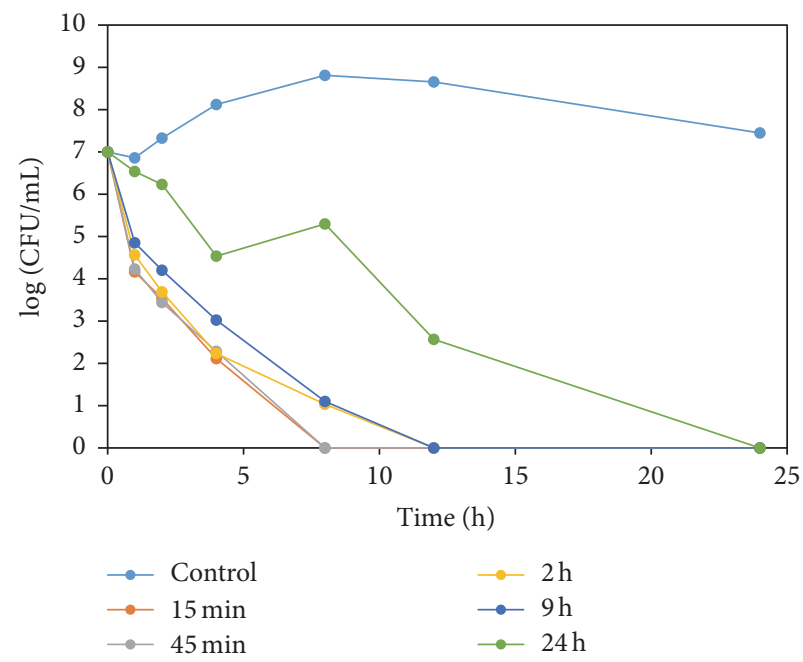

(b)

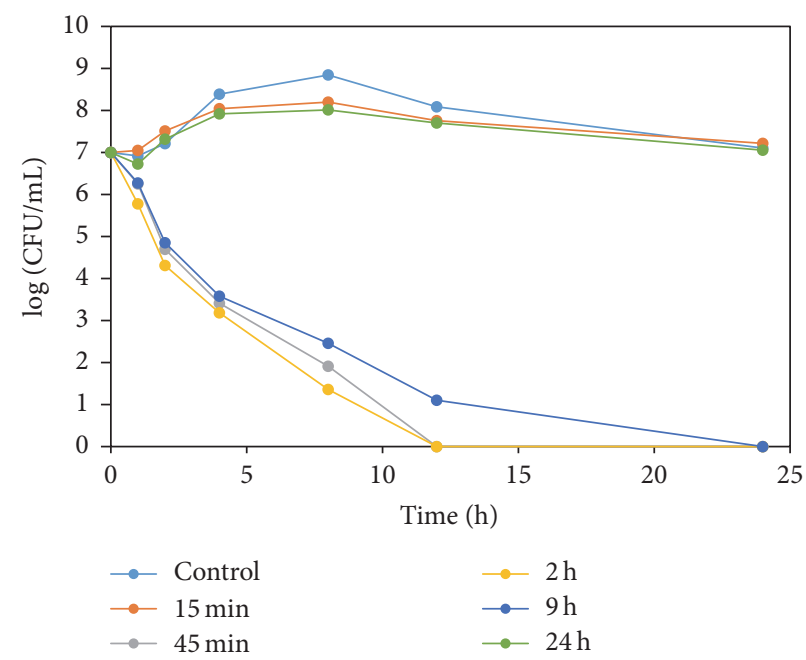

(c)

FIGURE 3: The results of ex vivo antibacterial effect of marbofloxacin using various routes of administration against 20 isolates of Actinobacillus pleuropneumoniae. (a) Intravenous, (b) intramuscular, and (c) peroral administration.

in this investigation is in accordance with previous studies in horses [33], beagle dogs [34], and hanwoo, Korean native cattle [35]. The current study demonstrated a favorable pharmacokinetic profile of marbofloxacin in pigs in terms of the rapid absorption of the drug from the tissues to the systemic circulation, prolonged duration of action as evident by the long terminal half-life, and excellent relative bioavailability. The probability of clinical success was evaluated through the use of the $\mathrm{AUC}_{0-24} / \mathrm{MIC}$ and $\mathrm{C}_{\max } / \mathrm{MIC}$ index.

We developed the LC-MS/MS method in the current study in order to identify and quantify marbofloxacin simultaneously from plasma. In LC-MS/MS chromatogram (Figure 1), peak of pure marbofloxacin was observed at about 2.4 minutes. When the plasma-spiked marbofloxacin solution was injected into the LC-MS/MS systems, the retention time and the mass to charge value $(\mathrm{m} / z)$ of the spiked marbofloxacin were found to be similar as it was obtained in the solution of pure compound (Figure 1). A fast, simple, and efficient extraction procedure is one of the essential parts of the quantification method in the present study. In this study, the totality of the plasma supernatant was dried by nitrogen evaporation to increase the signal of marbofloxacin. The major advantages of the present method were a shorter extraction time and that there is no need of a derivatization step. Therefore, the procedure described here enables the direct extraction of marbofloxacin without complementary purification steps.

The precision or coefficient of variation (\%) of this assay method was within the limits for the tested concentrations according to the guidelines for analytical method development and validation [36, 37], which indicates that the assay method is validated depending on the precision. The acceptance criterion for linearity is that the correlation coefficient $\left(r^{2}\right)$ should not be $<0.990$ for the least squares method of 
the analysis of the line [24]. The correlation coefficient of marbofloxacin was 0.9999 (Table 2). This result demonstrates the linearity of this method over a wide dynamic range.

The recovery percentage of this drug compound (Table 2) may be considered as slightly lower than expected, which could be attributable to the interference of the sample matrix or the slowness of extraction of this compound from the sample matrix. Moreover, the slightly lower recovery is justified in this case, as the expected recovery is dependent on the percentage of analyte in the matrix [37], indicating that the analytical method is validated. Specificity of the analytical method ensures that the signal measured comes from the desired compound and there is no interference from diluents, extract materials, and mobile phase. The data obtained in the validation study proved that the proposed method is validated and can be used for the determination and quantification of marbofloxacin in plasma.

The mean $( \pm S D)$ plasma concentration versus time curves of marbofloxacin at a dose of $2.5 \mathrm{mg} / \mathrm{kg}$ of body weight in pigs following i.v., i.m., and p.o. administration is shown in Figure 2. The administered dose is recommended to be daily in pigs [22]. Marbofloxacin was measurable in pig plasma from just after the administration to $72 \mathrm{~h}$ after i.v. and i.m. administration routes whereas, the drug substance was quantified from $15 \mathrm{~min}$ to $120 \mathrm{~h}$ after p.o. administration. Excluding the first part of the curve $(0-0.75 \mathrm{~h})$, the mean plasma concentrations of the administered three dosages were almost identical.

The longer elimination half-life of marbofloxacin observed in this study reflects the advantage of this drug in maintaining effective concentration in the body thereby allowing longer time for drug-pathogen interaction. The elimination half-life of marbofloxacin in pigs after i.v. administration was comparable with values in pigs, rabbits, and goats $[17,23,26]$ and longer than the value in sheep $(3.96 \mathrm{~h})$ [20]. After i.m. administration, the elimination half-life of marbofloxacin in the present study $(12.8 \mathrm{~h})$ was shorter than that obtained in pigs $(17.3 \mathrm{~h})$ [23], much longer than those obtained in goats (6.77 h) [17], horses (5.74 h) [33], calves (4.7 h) [38], and camels (7.98 h) [39], and also apparently longer than that obtained after i.v. administration in this study. This difference is probably the result of continued absorption of marbofloxacin from the i.m. injection site during the elimination phase, thereby prolonging the $t_{1 / 2}$ of the drug. The elimination half-life of marbofloxacin in our study following single p.o. administration in pig was estimated to be $8.6 \mathrm{~h}$, shorter than that in sea turtles $(13.33 \mathrm{~h})$ [40] but similar to that in chickens $(8.69 \mathrm{~h})$ [25]. The elimination half-life of this drug after p.o. administration in pig was largely higher in a previous investigation (23.14h) [25] than the value observed in the current study.

The $T_{\max }$ of marbofloxacin following single p.o. administration was estimated to be $1.58 \mathrm{~h}$, which is similar to that obtained in chickens $(1.48 \mathrm{~h})$ [23]. The $T_{\max }$ after i.m. administration in hanwoo cows $(0.95 \mathrm{~h})$ [35] was higher and in beagle dogs $(0.47 \mathrm{~h})$ [34] and sea turtles $(0.65 \mathrm{~h})$ [40] was comparable with the $T_{\max }$ value in pigs $(0.44 \mathrm{~h})$ in our study. $T_{\max }$ in sea turtles $(0.30 \mathrm{~h})$ [40] is similar to the value $(0.25 \mathrm{~h})$ in our study in pigs after i.v. administration. Marbofloxacin was rapidly absorbed with a $C_{\max }$ of $2.59 \pm 0.12 \mu \mathrm{g} / \mathrm{mL}$ achieved at $0.44 \pm 0.10 \mathrm{~h}$ after i.m. administration. The $C_{\max }$ values of marbofloxacin achieved after i.m. and p.o. administration were higher than the MIC break point of fluoroquinolones recommended against most susceptible bacterial species [32]. These values were higher than the values reported in goats $(1.87 \mu \mathrm{g} / \mathrm{mL})$ [17], rabbits $(2.04 \mu \mathrm{g} / \mathrm{mL})$ [20], and sheep $(0.80 \mu \mathrm{g} / \mathrm{mL})$ [25]. Even, the $C_{\max }$ value of marbofloxacin in this study was higher than the previously reported values in pigs $(1.81 \mu \mathrm{g} / \mathrm{mL}$ in i.m. and $1.03 \mu \mathrm{g} / \mathrm{mL}$ in p.o.) [23]. The relative bioavailability of marbofloxacin was calculated to be $104.60 \pm 5.70 \%$ after i.m. administration, while high bioavailability has also been reported in rabbits (123.30\%) [40] and in goats (100.74\%) [17]. The relative bioavailability obtained for marbofloxacin after p.o. application was $94.35 \pm 8.90 \%$, which is in between the bioavailabilities $(91.50 \pm 13.70 \%$ and $107.90 \pm 13.40 \%)$ reported previously $[22,23]$. In this study, higher intramuscular marbofloxacin bioavailability (more than 100\%) may be because of the prolonged elimination half-lives after i.m. administration that could have induced higher AUC values.

The ex vivo killing study indicates concentration-dependent antibacterial effect of marbofloxacin; increasing the drug concentration led to more-rapid killing of all tested bacterial strains. The values of ex vivo antibacterial effects are rational according to the in vitro MIC and MBC data, and serum concentrations of marbofloxacin at different time points. Roughly, the serum concentrations of marbofloxacin were above the in vitro $\mathrm{MBC}$ concentrations of most of the strains at time $(0-9) h,(0.25-9) h$ and $(0.5-12) h$ for i.v., i.m. and p.o. administrations, respectively. Moreover, the elimination half-lives of marbofloxacin from all of these dosage forms in pigs are longer, which also justifies the ex vivo antibacterial effect of marbofloxacin. The integration of PK data with the PD data presents a better approach to dose titration studies for selecting rational dosage regimens in veterinary medicine [27]. Furthermore, the PK/PD indices of the same drug against different pathogens also vary. So, it is of great importance to study the PK/PD indices of fluoroquinolones against individual pathogen [41]. In the current study, the PK data obtained from a single i.v., i.m., and p.o. administration of marbofloxacin in pigs was integrated with PD (ex vivo) data using A. pleuropneumoniae as a model organism. Large $\mathrm{AUC}_{0-24 \mathrm{~h}} / \mathrm{MIC}$ and $C_{\max } / \mathrm{MIC}$ ratios were obtained for A. pleuropneumonia isolates following i.v., i.m., and p.o. administration of marbofloxacin in pigs (Table 5). $\mathrm{PK} / \mathrm{PD}$ indices, such as $C_{\max } / \mathrm{MIC}$ and $\mathrm{AUC}_{0-24 \mathrm{~h}} / \mathrm{MIC}$ values of the target organism, have been used to predict the clinical efficacy of antibacterial agents. Another important PK/PD parameter to describe drug efficacy is the time during which the drug concentration exceeds the MIC ( $T>$ MIC) [42]. It is generally recommended that $T>$ MIC should be at least $50 \%$ of the dosage interval to ensure an optimal bactericidal effect $[42,43]$. During the present study, to optimize the marbofloxacin dosage regimen, we also calculated the $T>$ MIC at a dose of $2.50 \mathrm{mg} / \mathrm{kg}$ of body weight in pigs after i.v., i.m., and p.o. administration. 
The values of PK/PD parameters (AUC/MIC, $C_{\max } / \mathrm{MIC}$, and $T>$ MIC) obtained in this study were compared with the PK/PD values in previous studies. The AUC/MIC and $T$ > MIC of marbofloxacin in serum against Mannheimia haemolytica after i.v. and i.m. administration to calf at a dosage of $2.0 \mathrm{mg} / \mathrm{kg}$ were $249.75 \pm 25.87$ and $252.67 \pm 9.16 \mathrm{~h}$ and $22.69 \pm 1.69$ and $22.68 \pm 0.79 \mathrm{~h}$, respectively. The ratio of $C_{\max }$ and MIC in the same situation after i.m. administration was $37.60 \pm 1.87$ [1], where the AUC/MIC values in calf are similar as obtained in the current study. In sheep, the AUC/MIC in serum after i.v. and i.m. dosing against Mannheimia haemolytica were 120.2 and $135.5 \mathrm{~h}$, respectively. After i.m. administration $T>\mathrm{MIC}$ was $10.5 \mathrm{~h}$, and $C_{\max } / \mathrm{MIC}$ was 21.1 which is comparable with the $C_{\max } / \mathrm{MIC}$ value of this study [20]. The AUC/MIC, $C_{\max } / \mathrm{MIC}$, and $T>$ MIC of marbofloxacin against Escherichia coli after oral administration $(2 \mathrm{mg} / \mathrm{kg}$ of body weight $)$ in turkeys were $73.69 \pm$ $25.54 \mathrm{~h}, 5.35 \pm 2.31$, and $10.9 \mathrm{~h}$, which are about 4 times lower than the values of corresponding parameters in the present study [44]. $\mathrm{AUC}_{24 \mathrm{~h}} / \mathrm{MIC}$ and $T>\mathrm{MIC}$ of marbofloxacin against Staphylococcus pseudintermedius after i.v. and i.m administration $(2 \mathrm{mg} / \mathrm{kg}$ body weight) in beagle dogs were $67.76 \pm 1.23 \mathrm{~h}$ and $91.18 \pm 2.61 \mathrm{~h}$ and $9.83 \pm 1.72$ and $15.50 \pm$ 6.68 , respectively, and the $C_{\max } / \mathrm{MIC}$ after i.m. administration in the same situation was $13.04 \pm 1.03$. All the values of $\mathrm{PK} / \mathrm{PD}$ parameters in beagle dogs are about half the values obtained in the current study [34]. The $\mathrm{AUC}_{0-24 \mathrm{~h}} / \mathrm{MIC}$ values $253.86,264.10$, and $239.53 \mathrm{~h}$ after i.v., i.m., and p.o. administration, respectively, are likely to provide a good antibacterial outcome. So that, the $2.50 \mathrm{mg} / \mathrm{kg}$ dosage may be regarded as appropriate for the strains of A. pleuropneumonia used in this study [44], as the $\mathrm{AUC}_{0-24 \mathrm{~h}} / \mathrm{MIC}$ ratio of $>125 \mathrm{~h}$ and a $C_{\max } / \mathrm{MIC}$ ratio of $>10$ are generally considered the best indicators of activity for agents with concentrationdependent killing and were usually used as a threshold for successful therapeutic outcome of fluoroquinolones against gram-negative bacteria [45]. Nevertheless, these thresholds may be different for some fluoroquinolones. The greatest influence for the differences was the immune status of the animal. The plasma concentrations were also greater than the MICs of the tested drug. It can be assumed that marbofloxacin concentration in the site of action was at least very similar to that observed in plasma due to the high bioavailability, low protein binding, and tissue distribution reported for fluoroquinolones [46].

\section{Conclusions}

The current study demonstrated promising pharmacokinetic profiles of i.v., i.m., and p.o. formulations of marbofloxacin in pigs. Further, the current study established the correlation between the plasma concentration of marbofloxacin and its in vitro activity against an important bacterial pathogen, $A$. pleuropneumonia. It was also revealed in this study that the marbofloxacin was completely absorbed and slowly eliminated after single i.v., i.m., and p.o. administration in healthy pigs. The mean marbofloxacin plasma concentrations at $24 \mathrm{~h}$ after i.v., i.m., and p.o. administration at a dose of $2.50 \mathrm{mg} / \mathrm{kg}$ were all higher than $0.25 \mu \mathrm{g} / \mathrm{mL}$, which are above or very close to the $\mathrm{MIC}_{90}$ against most major pathogenic bacteria $[47,48]$. So, a marbofloxacin dosage of $2.50 \mathrm{mg} / \mathrm{kg}$ of body weight by i.v., i.m., or p.o. administration to pigs with $24 \mathrm{~h}$ dosing interval will provide effective treatment for the infection of pig by A. pleuropneumonia. Additional studies may also be necessary to confirm the penetration of marbofloxacin in diseased tissues, so that its potential use in clinical situations could be assessed.

\section{Conflicts of Interest}

None of the authors have any conflicts of interest to declare.

\section{Authors' Contributions}

Md. Akil Hossain and Hae-chul Park contributed equally to this study.

\section{Acknowledgments}

This study was supported by Veterinary Science Research Project grants from the Korean Animal and Plant Quarantine Agency (Grant no. B-1543073-2015-17-0102). The authors are grateful to Dr. Suk-Kyung Lim of the Bacterial Disease Division, Animal and Plant Quarantine Agency, for kindly providing bacterial isolates.

\section{References}

[1] F. Shojaee AliAbadi and P. Lees, "Pharmacokinetics and pharmacokinetic/pharmacodynamic integration of marbofloxacin in calf serum, exudate and transudate," Journal of Veterinary Pharmacology and Therapeutics, vol. 25, no. 3, pp. 161-174, 2002.

[2] S. A. Brown, "Fluoroquinolones in animal health," Journal of Veterinary Pharmacology and Therapeutics, vol. 19, no. 1, pp. 114, 1996.

[3] C. Vilalta, H. Giboin, M. Schneider, F. El Garch, and L. Fraile, "Pharmacokinetic/pharmacodynamic evaluation of marbofloxacin in the treatment of Haemophilus parasuis and Actinobacillus pleuropneumoniae infections in nursery and fattener pigs using Monte Carlo simulations," Journal of Veterinary Pharmacology and Therapeutics, vol. 37, no. 6, pp. 542-549, 2014.

[4] M. Gottschalk and D. J. Taylor, "Actinobacillus pleuropneumoniae," in Diseases of Swine, E. S. Barbara, J. Z. Jeffrey, D. A. Sylvie, and J. T. David, Eds., pp. 343-355, Blackwell Publishing, Ames, Iowa, USA, 9th edition, 2006.

[5] J. I. MacInnes and S. Rosendal, "Prevention and control of Actinobacillus (Haemophilus) pleuropneumoniae infection in swine: a review," Canadian Veterinary Journal, vol. 29, no. 7, pp. 572$574,1988$.

[6] H. Vigre, Ø. Angen, K. Barfod, D. T. Lavritsen, and V. Sørensen, "Transmission of Actinobacillus pleuropneumoniae in pigs under field-like conditions: emphasis on tonsillar colonisation and passively acquired colostral antibodies," Veterinary Microbiology, vol. 89, no. 2-3, pp. 151-159, 2002.

[7] D. T. Lavritsen, K. Barfod, Ø. Angen, and V. Sørensen, "Carrier animals in a Danish high-health multiplying herd recently infected with Actinobacillus pleuropneumoniae serotype 2," in Proceedings of the 17th International Pig Veterinary Society Congress, vol. 1, p. 183, Ames, Iowa USA, June 2002. 
[8] M. Vanni, M. Merenda, G. Barigazzi et al., "Antimicrobial resistance of Actinobacillus pleuropneumoniae isolated from swine," Veterinary Microbiology, vol. 156, no. 1-2, pp. 172-177, 2012.

[9] R. Gouvea, F. F. dos Santos, M. H. C. de Aquino, and A. V. L. Pereira, "Fluoroquinolones in industrial poultry production, bacterial resistance and food residues: a review," Brazilian Journal of Poultry Science, vol. 17, no. 1, pp. 1-10, 2015.

[10] Animal \& Veterinary, Extralabel Use and Antimicrobials, Food and Drug Administration, Silver Spring, Md, USA, 2014.

[11] A. Wasley and V. Parsons, Banned in America, Soaring Use in Britain: The Poultry Farm Drugs That Put Human Lives at Risk, The Bureau of Investigative Journalism, London, UK, 2016.

[12] T. Trouchon and S. Lefebvre, "A review of enrofloxacin for veterinary use," Open Journal of Veterinary Medicine, vol. 6, no. 2, pp. 40-58, 2016.

[13] E. E. Baroni, C. Rodríguez, G. Crudeli et al., "Pharmacokinetics of marbofloxacin, after single intravenous administrations, in buffaloes calves," Italian Journal of Animal Science, vol. 6, supplement 2, pp. 838-841, 2007.

[14] G. Elias, J.-S. Lee, M.-H. Hwang et al., "Pharmacokinetics and pharmacokinetic/pharmacodynamic integration of orbifloxacin in Korean Hanwoo cattle," Journal of Veterinary Pharmacology and Therapeutics, vol. 32, no. 3, pp. 219-228, 2009.

[15] A. Regnier, D. Concordet, M. Schneider, B. Boisramé, and P.-L. Toutain, "Population pharmacokinetics of marbofloxacin in aqueous humor after intravenous administration in dogs," American Journal of Veterinary Research, vol. 64, no. 7, pp. 889893, 2003.

[16] M. Shem-Tov, G. Ziv, A. Glickman, and A. Saran, "Pharmacokinetics and penetration of marbofloxacin from blood into the milk of cows and ewes," Zentralblatt für Veterinärmedizin Reihe A, vol. 44, no. 9-10, pp. 511-519, 1997.

[17] S. Waxman, C. Rodríguez, F. González, M. L. De Vicente, M. I. San Andrés, and M. D. San Andrés, "Pharmacokinetic behavior of marbofloxacin after intravenous and intramuscular administrations in adult goats," Journal of Veterinary Pharmacology and Therapeutics, vol. 24, no. 6, pp. 375-378, 2001.

[18] M. Schneider, M. Vallé, F. Woehrlé, and B. Boisramé, "Pharmacokinetics of marbofloxacin in lactating cows after repeated intramuscular administrations and pharmacodynamics against mastitis isolated strains," Journal of Dairy Science, vol. 87, no. 1, pp. 202-211, 2004.

[19] G. A. Albarellos, V. E. Kreil, and M. F. Landoni, "Pharmacokinetics of ciproloxacin after single intravenous and repeat oral administration to cats," Journal of Veterinary Pharmacology and Therapeutics, vol. 27, no. 3, pp. 155-162, 2004.

[20] P. K. Sidhu, M. F. Landoni, F. S. Aliabadi, and P. Lees, "PK-PD integration and modeling of marbofloxacin in sheep," Research in Veterinary Science, vol. 88, no. 1, pp. 134-141, 2010.

[21] E. Heinen, "Comparative serum pharmacokinetics of the fluoroquinolones enrofloxacin, difloxacin, marbofloxacin, and orbifloxacin in dogs after single oral administration," Journal of Veterinary Pharmacology and Therapeutics, vol. 25, no. 1, pp. 1-5, 2002.

[22] M. Schneider, A. Paulin, F. Dron, and F. Woehrlé, "Pharmacokinetics of marbofloxacin in pigs after intravenous and intramuscular administration of a single dose of $8 \mathrm{mg} / \mathrm{kg}$ : dose proportionality, influence of the age of the animals and urinary elimination," Journal of Veterinary Pharmacology and Therapeutics, vol. 37, no. 6, pp. 523-530, 2014.
[23] H. Ding, Y. Li, Z. Chen, M. Rizwan-Ul-Haq, and Z. Zeng, "Plasma and tissue cage fluid pharmacokinetics of marbofloxacin after intravenous, intramuscular, and oral singledose application in pigs," Journal of Veterinary Pharmacology and Therapeutics, vol. 33, no. 5, pp. 507-510, 2010.

[24] International Conference on Harmonization (ICH), Validation of Analytical Procedures d PA/PH/OMCL (05) 47 DEF, OMCL Network/EDQM of the Council of Europe, 2005.

[25] P. Marín, L. F. Álamo, E. Escudero, E. Fernández-Varón, V. Hernandis, and C. M. Cárceles, "Pharmacokinetics of marbofloxacin in rabbit after intravenous, intramuscular, and subcutaneous administration," Research in Veterinary Science, vol. 94, no. 3, pp. 698-700, 2013.

[26] J. Gloede, C. Scheerans, H. Derendorf, and C. Kloft, "In vitro pharmacodynamic models to determine the effect of antibacterial drugs," The Journal of Antimicrobial Chemotherapy, vol. 65, no. 2, pp. 186-201, 2010.

[27] P. L. Toutain and P. Lees, "Integration and modelling of pharmacokinetic and pharmacodynamic data to optimize dosage regimens in veterinary medicine," Journal of Veterinary Pharmacology and Therapeutics, vol. 27, no. 6, pp. 467-477, 2004.

[28] M. E. Klepser, E. J. Ernst, C. R. Petzold, P. Rhomberg, and G. V. Doern, "Comparative bactericidal activities of ciprofloxacin, clinafloxacin, grepafloxacin, levofloxacin, moxifloxacin, and trovafloxacin against Streptococcus pneumoniae in a dynamic in vitro model," Antimicrobial Agents and Chemotherapy, vol. 45, no. 3, pp. 673-678, 2001.

[29] K. J. Madaras-Kelly and T. A. Demasters, "In vitro characterization of fluoroquinolone concentration/MIC antimicrobial activity and resistance while simulating clinical pharmacokinetics of levofloxacin, ofloxacin, or ciprofloxacin against Streptococcus pneumoniae," Diagnostic Microbiology and Infectious Disease, vol. 37, no. 4, pp. 253-260, 2000.

[30] ICH guidelines Q1A (R2), Stability Testing of New Drug Substances and Products, International Conference on Harmonization, Geneva, Switzerland, 2003.

[31] ICH guidelines Q2 (R1), Validation of Analytical Procedures: Text and Methodology, International Conference on Harmonization, Geneva, Switzerland, 2005.

[32] CLSI (Clinical and Laboratory Standards Institute), Performance Standards for Antimicrobial Susceptibility Testing, 17th Informational supplement, Document M100-S17, Clinical and Laboratory Standards Institute, Wayne, Pa, USA, 2007.

[33] M. Carretero, C. Rodríguez, M. I. San Andrés et al., "Pharmacokinetics of marbofloxacin in mature horses after single intravenous and intramuscular administration," Equine Veterinary Journal, vol. 34, no. 4, pp. 360-365, 2002.

[34] S. Yohannes, E. G. Awji, S.-J. Lee, and S.-C. Park, "Pharmacokinetics and pharmacokinetic/pharmacodynamic integration of marbofloxacin after intravenous and intramuscular administration in beagle dogs," Xenobiotica, vol. 45, no. 3, pp. 264-269, 2015.

[35] S. Belew, J.-Y. Kim, M. A. Hossain et al., "Pharmacokinetics of marbofloxacin after intravenous and intramuscular administration in Hanwoo, Korean native cattle," Journal of Veterinary Medical Science, vol. 77, no. 3, pp. 327-329, 2015.

[36] Guidance for Industry, Bioanalytical Method Validation, Food and Drug Administration, Maryland, Md, USA, 2013.

[37] Standard Format and Guidance for AOAC Standard Method Performance Requirement, AOAC International, Maryland, Md, USA, 2011. 
[38] R. Laraje, A. Talmi, R. Bounaga, M. Bengoumi, A. El Hraiki, and M. Laurentie, "Comparative pharmacokinetics of marbofloxacin after a single intramuscular administration at two dosages to camels (Camelus dromedarius)," Journal of Veterinary Pharmacology and Therapeutics, vol. 29, no. 3, pp. 229-231, 2006.

[39] M. Ismail and Y. A. El-Kattan, "Comparative pharmacokinetics of marbofloxacin in healthy and Mannheimia haemolytica infected calves," Research in Veterinary Science, vol. 82, no. 3, pp. 398-404, 2007.

[40] P. Marín, O. R. Lai, P. Laricchiuta et al., "Pharmacokinetics of marbofloxacin after a single oral dose to loggerhead sea turtles (Caretta caretta)," Research in Veterinary Science, vol. 87, no. 2, pp. 284-286, 2009.

[41] S. Jian, X. Xia, H. Rui-Juan et al., "In vitro Dynamic Pharmacokinetic/Pharamcodynamic (PK/PD) study and COPD of Marbofloxacin against Haemophilus parasuis," BMC Veterinary Research, vol. 11, article 293, 2015.

[42] B. Zhang, X. Gu, X. Li et al., "Pharmacokinetics and ex-vivo pharmacodynamics of cefquinome against Klebsiella pneumonia in healthy dogs," Journal of Veterinary Pharmacology and Therapeutics, vol. 37, no. 4, pp. 367-373, 2014.

[43] L. Winther, K. E. Baptiste, and C. Friis, "Antimicrobial disposition in pulmonary epithelial lining fluid of horses, part III. Cefquinome," Journal of Veterinary Pharmacology and Therapeutics, vol. 34, no. 5, pp. 482-486, 2011.

[44] A. M. Haritova, N. V. Rusenova, P. R. Parvanov, L. D. Lashev, and J. Fink-Gremmels, "Integration of pharmacokinetic and pharmacodynamic indices of marbofloxacin in turkeys," Antimicrobial Agents and Chemotherapy, vol. 50, no. 11, pp. 3779-3785, 2006.

[45] P. L. Toutain, J. R. E. Del Castillo, and A. Bousquet-Mélou, “The pharmacokinetic-pharmacodynamic approach to a rational dosage regimen for antibiotics," Research in Veterinary Science, vol. 73, no. 2, pp. 105-114, 2002.

[46] M. Martinez, P. McDermott, and R. Walker, "Pharmacology of the fluoroquinolones: a perspective for the use in domestic animals," The Veterinary Journal, vol. 172, no. 1, pp. 10-28, 2006.

[47] M. Spreng, J. Deleforge, V. Thomas, B. Boisramé, and H. Drugeon, "Antibacterial activity of marbofloxacin. A new fluoroquinolone for veterinary use against canine and feline isolates," Journal of Veterinary Pharmacology and Therapeutics, vol. 18, no. 4, pp. 284-289, 1995.

[48] H. B. Drugeon, V. Thomas, L. Guillardeau, and E. Thomas, "Antibacterial activity of marbofloxacin against bovine respiratory isolates," Journal of Veterinary Pharmacology and Therapeutics, vol. 20, pp. 138-139, 1997. 

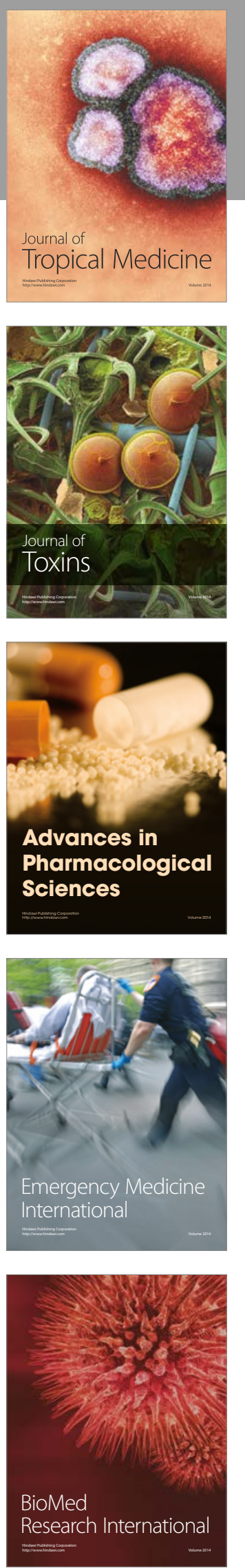
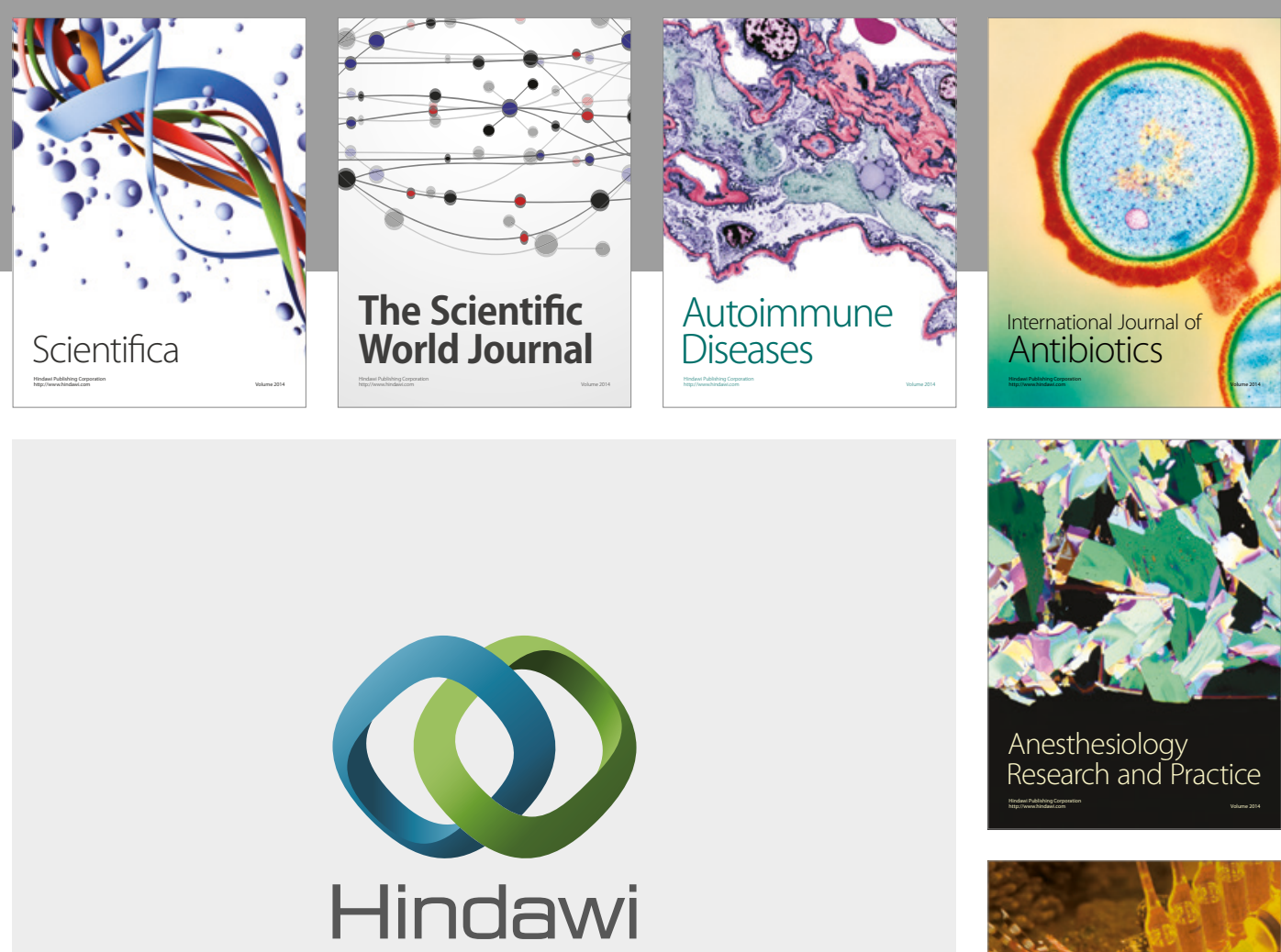

Submit your manuscripts at

https://www.hindawi.com
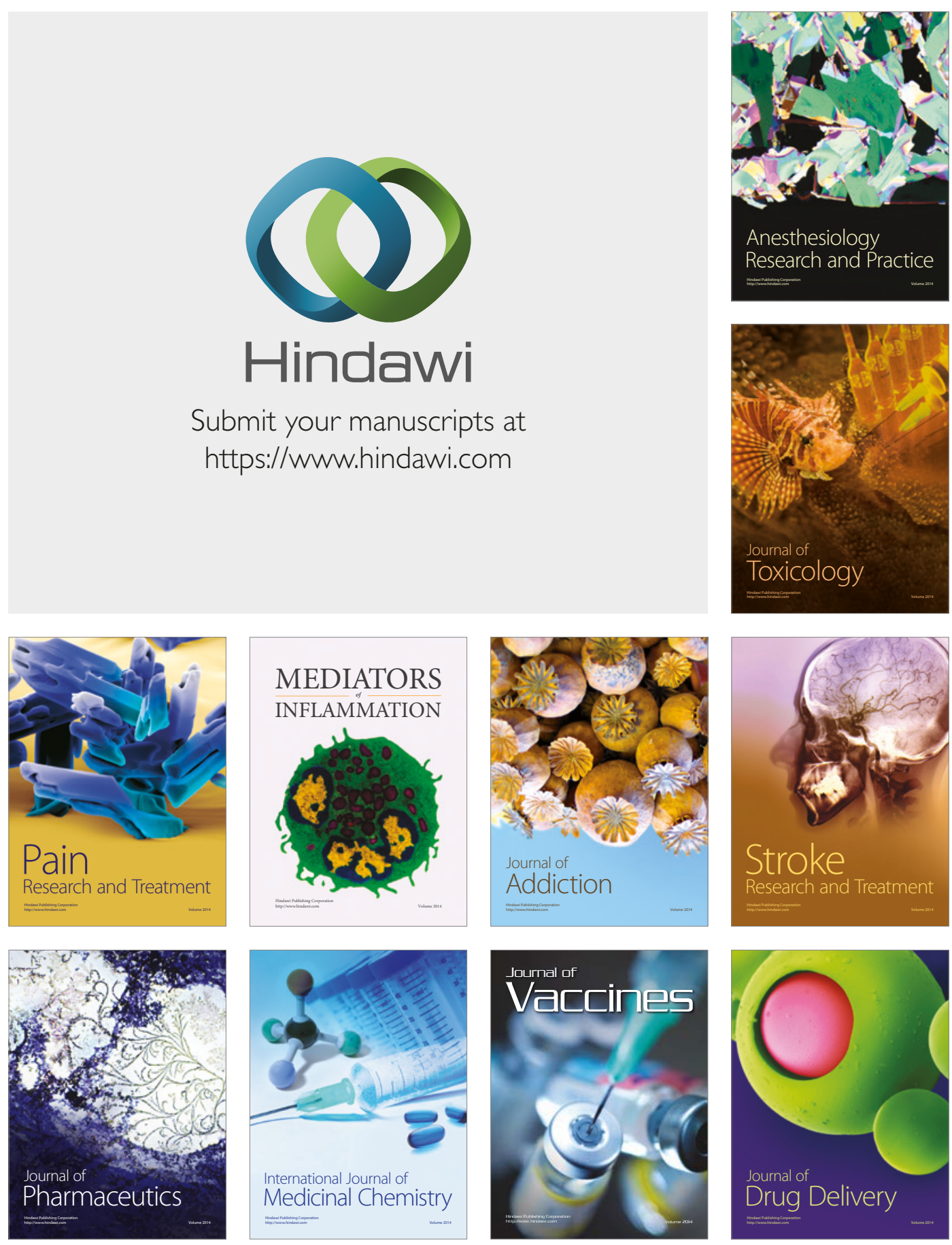